\title{
Anatomía de los órganos vegetativos de dos especies de Atriplex (Chenopodiaceae) de Venezuela
}

\section{Damelis Jáuregui, Mercedes Castro, Thirza Ruiz-Zapata \& Marlene Lapp}

Instituto de Botánica Agrícola, Facultad de Agronomía, Universidad Central de Venezuela, Prolongación Av. 19 de Abril, Maracay, Aragua, Venezuela; jaureguid@gmail.com, laportte@hotmail.com, thirzar2409@yahoo.com, marlenelapp@gmail.com

Recibido 17-II-2014. Corregido 04-VII-2014. Aceptado 13-VIII-2014.

\begin{abstract}
Anatomy of the vegetative organs of two species of Atriplex (Chenopodiaceae) from Venezuela. In Venezuela, Atriplex is represented by A. cristata and A. oestophora, the latter being endemic; they inhabit coastal areas with high temperatures, high solar radiation and sandy soils with high salt content. This work aimed to provide information to facilitate and clarify these species taxonomic delimitation, throughout the study of the anatomy of their vegetative organs; this may also clarify our understanding of their adaptability to soil and climatic conditions prevailing in areas they inhabit. The plant material was collected from at least three individuals of each species in Punta Taima Taima and Capatárida, Falcon. Segments of roots, located near the neck and towards the apex, apical, middle and basal internodes of stems, were taken; and of leaves, located in the middle portion of plants. This material was fixed in FAA (formaldehyde, acetic acid, 70\% ethanol) until processing. Semipermanent and permanent microscope slides were prepared with transverse or longitudinal sections, made using a razor (free-hand) or a rotation microtome, in this latter case, after paraffin embedding; besides, additional plates were mounted with portions of leaf epidermis, obtained by the maceration technique. The sections were stained with aqueous toluidine blue $(1 \%)$ or safranin-fast-green, and mounted in water-glycerin or in Canada balsam. In order to calculate the vulnerability index, the vessel diameter in the vascular rings of roots, as well as their density, were quantified. Our results revealed structural features in the different organs, that resulted of taxonomic value and allowed the distinction of the species: in the leaf, the presence of aquifer tissue, the number of vascular bundles and their organization in the midrib, and the collenchyma differentiation in this part of the leaf; in the roots, the xylem and phloem arrangement in the growth rings, the nature of conjunctive tissue, and the presence of included phloem in one species. In addition, the species showed typical anatomical features of halophytes and xerophytes, such as: high density of trichomes on leaves and young stems which act as salt secreting glands, abundant sclerenchyma in stems and roots, water storage tissue and Kranz anatomy in leaves, narrow cortical region in young roots, presence of cambial variants in stems and roots, as well as short and narrow xylem vessels. Vulnerability index calculations indicated that both species tend to assure conduction but not the efficiency of the system. Atriplex species have anatomical characters which facilitate their adaptation to the special conditions prevailing in their habitats and that may be used for taxonomic delimitation. Rev. Biol. Trop. 62 (4): 1625-1636. Epub 2014 December 01.
\end{abstract}

Key words: anatomy, Atriplex, halophyte species, leaf, stem, root.

Cuénoud et al. (2002); Kadereit, Borsch, Weising, y Freitag (2003) demostraron que Amaranthaceae y Chenopodiaceae forman un clado monofilético, por lo que las han reunido como Amaranthaceae s.l., asumiendo que Chenopodiaceae es parafilética respecto a Amaranthaceae. Miembros de las Chenopodiaceae conforman las Chenopodoideae en esa clasificación. No obstante, la identidad de este grupo aún no está definida suficientemente, por lo cual la mayoría de la literatura florística y de los estudios ecológicos se refieren a Amaranthaceae y Chenopodiaceae por separado (Müller \& Borsh, 2005). 
Chenopodiaceae comprende alrededor de 102 géneros y unas 1400 especies de amplia distribución mundial, aunque, en su mayoría, están confinadas a áreas xéricas o salitrosas, por lo que presentan en sus órganos caracteres xeromórficos (Pérez \& Hermann, 2009).

Atriplex L. es uno de los géneros más importante en cuanto al número de especies en Chenopodiaceae. Tiene entre 200-300 especies, de difícil delimitación taxonómica, debido a la existencia de polimorfismo en los caracteres y de individuos con características intermedias entre las especies aceptadas (Flores, 1992; Kadereit, Mavrodiev, Zacharias, \& Sukhorukov, 2010). Sus especies muestran un gran potencial para la rehabilitación de terrenos degradados y en la producción de forraje y combustible en zonas áridas (Mulas \& Mulas, 2004; Frayssinet, González, D’Ambrogio, Fernández, \& Furlan, 2007; Enríquez, Parra, \& Ramírez, 2011). Se ha indicado que este taxón tiene distribución mundial y que en Suramérica se localiza la mayor cantidad de endemismos (Osmond et al. como se citó en McArthur \& Sanderson, 1983). En Venezuela se citan tres especies (Hokche, Berry, \& Huber, 2008); no obstante, Ruiz-Zapata, Castro, y Wingfield (2013) indican que crecen sólo dos: A. pentandra (Jacq.) Standl. y A. oestophora Blake, esta última considerada endémica para el país y presente en los estados Falcón y Zulia; ambas especies se desarrollan en lugares con suelos arenosos y salinos cercanos a costas marinas. Wingfield (com. pers.) señala que $A$. pentandra (Jacq.) Standl. es sinónimo de A. cristata Humb. et Bonpl. ex Willd., tal como lo discute Howard (1973), por lo cual las especies presentes en Venezuela son: A. cristata Humb. et Bonpl. ex Willd. y A. oestophora Blake.

Las especies a estudiar, tal como se ha referido para otras del género (Mozafar \& Goodin, 1970; Wang, Showalter, \& Ungar, 1997; Frayssinet et al., 2007; Grigore \& Toma, 2007; Sayed-Hussin, 2007), se caracterizan en general por su capacidad para tolerar condiciones ambientales extremas; en particular los ambientes áridos y suelos salinos de las costas del país; Medina, Francisco, Wingfield, y Casañas (2008) las catalogaron como halófitas, por lo que posiblemente los órganos vegetativos de estas especies presenten rasgos anatómicos que posibiliten su adaptación a estas condiciones. El objetivo de este trabajo fue contribuir con la caracterización anatómica de las especies de Atriplex presentes en Venezuela, aportando rasgos para facilitar su delimitación taxonómica y precisar caracteres en sus órganos vegetativos que contribuyan a su adaptabilidad a las condiciones edafoclimáticas imperantes en las zonas donde habitan.

\section{MATERIALES Y MÉTODOS}

El material vegetal fue colectado de tres individuos, en Punta Taima Taima (03/07/12) y en Capatárida (18/04/12), estado Falcón, Venezuela. Los especímenes de referencia (Castro et al. 436 y González et al. 13) fueron depositados en el Herbario Víctor M. Badillo (MY). Se tomaron porciones de raíces próximas al cuello y ubicadas hacia el ápice de la raíz principal; entrenudos apicales, medios y basales de los tallos, y hojas ubicadas en la porción media de las plantas. Dicho material se subdividió y fijó en FAA (formaldehido, ácido acético, etanol $70 \%$ ) en una relación 5:5:90, hasta su procesamiento. Se realizaron secciones a mano alzada, las cuales se tiñeron con azul de toluidina acuosa al 1\% (Johansen, 1940) o con safranina-azul de astra (Krauss \& Arduin, 1997), en ambos casos se montaron en agua-glicerina $(\mathrm{V}: \mathrm{V})$. Asimismo, se siguió el protocolo establecido por Johansen (1940) para lograr su inclusión en parafina. Las secciones en este caso, se realizaron con un micrótomo de rotación, se tiñeron con safranina-fast green (Johansen, 1940) y se montaron en bálsamo de Canadá. Para obtener las epidermis foliares, se utilizó hipoclorito de sodio comercial $(5.25 \%)$ diluido a la mitad de su concentración. Las porciones de tejido obtenidas se tiñeron y montaron de forma semejante a lo expuesto para los cortes a mano alzada. Los montajes se observaron y analizaron bajo un microscopio óptico Nikon E200 con cámara digital incorporada, Evolution LC. Se hicieron mediciones relativas al diámetro de los vasos 
y su densidad en las secciones transversales de las raíces en crecimiento secundario de las dos especies, con el fin de calcular el índice de vulnerabilidad de las mismas (Carlquist, 1977); para ello se usó un ocular micrométrico acoplado a un microscopio previamente calibrado. Dichas determinaciones se realizaron en cinco secciones diferentes obtenidas de cada individuo muestreado, realizando en cada una tres mediciones, para un total de 45 observaciones por especie.

\section{RESULTADOS}

Las hojas de ambas especies tienen epidermis uniestratificada en las dos superficies; en sección transversal las células son subglobosas a globosas en $A$. cristata (Fig. 1A) y rectangulares a subglobosas en A. oestophora (Fig. 1B); en vista frontal, en los dos taxones se presentan con paredes rectas y delgadas (Fig. 1C, Fig. 1D). Los estomas, anomocíticos (Fig. 1C, Fig. 1D), se distinguen tanto en la epidermis adaxial
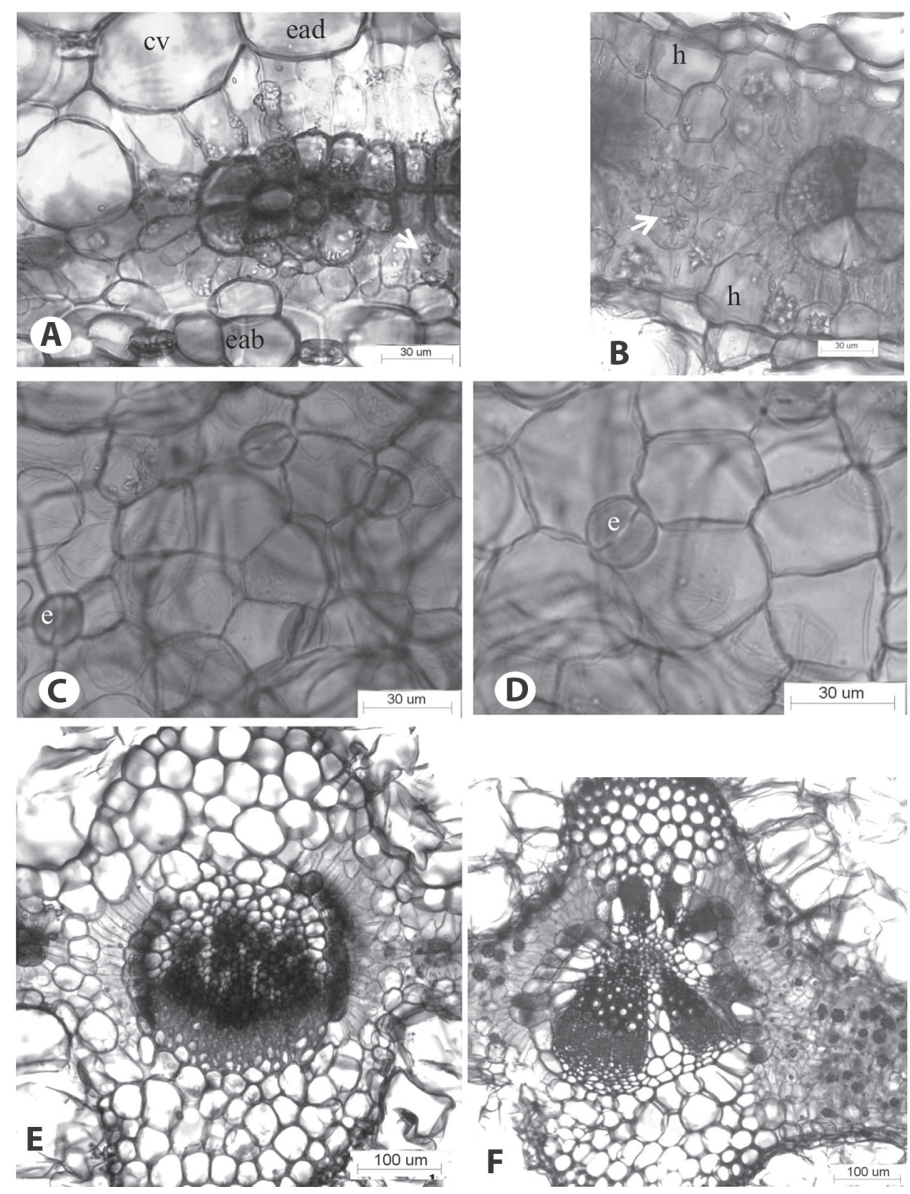

Fig. 1. A-B. Secciones transversales de la lámina foliar de A. cristata y A. oestophora, nótense células voliminosas en epidermis adaxial de $A$. cristata. C-D. Vistas paradérmicas de las epidermis abaxiales de A. cristata y A. oestophora. E-F. Sección transversal de la nervadura central de $A$. cristata y $A$. oestophora. Cristales (flecha), cv: células voluminosas, ead: epidermis adaxial, eab: epidermis abaxial, e: estoma, h: hipodermis.

Fig. 1. A-B. Transversal sections of the blade of A. cristata and A. oestophora, observe bulky cells in adaxial epidermis of A. cristata. C-D. Paradermal views of the abaxial epidermis of $A$. cristata and $A$. oestophora. E-F. Transversal sections of the midrib of $A$. cristata and A. oestophora. crystals (arrow), cv: bulky cell, ead: adaxial epidermis, eab: abaxial epidermis, e: stoma, h: hypodermis. 
como abaxial. Tricomas vesiculares cubren las dos epidermis en alta densidad, los mismos se caracterizan por un pie corto y delgado y una cabezuela globosa, unicelular, relativamente grande. En el mesofilo se aprecia claramente anatomía Kranz, caracterizada por la presencia de una vaina parenquimática alrededor de los haces vasculares, cuyas células tienen cloroplastos evidentes y paredes más gruesas que el resto de células del mesofilo; estas últimas muestran un arreglo radiado (Fig. 1A, Fig. 1B). Es evidente una capa de células incoloras tanto adaxial como abaxial en $A$. oestophora, que puede tratarse de una hipodermis, pero requiere confirmación mediante un estudio ontogenético (Fig. 1B). Cristales tipo drusa están presentes en las dos especies, pero son más abundantes en A. oestophora (Fig. 1A, Fig. 1B).

La nervadura central (Fig. 1E, Fig. 1F) tiene epidermis de células cuadrangulares, de menor tamaño en la epidermis abaxial; seguidamente se localiza parénquima en $A$. cristata y colénquima seguido de parénquima en $A$. oestophora. La organización del tejido vascular difiere a lo largo de la hoja y entre una especie y otra, está constituido en la base de la lámina por tres haces en $A$. cristata y cincoseis en $A$. oestophora; este número disminuye hacia el ápice foliar, contándose sólo uno en cada especie. Los haces se arreglan en forma de arco, con xilema hacia la superficie adaxial en el caso de $A$. cristata; en la otra especie, se
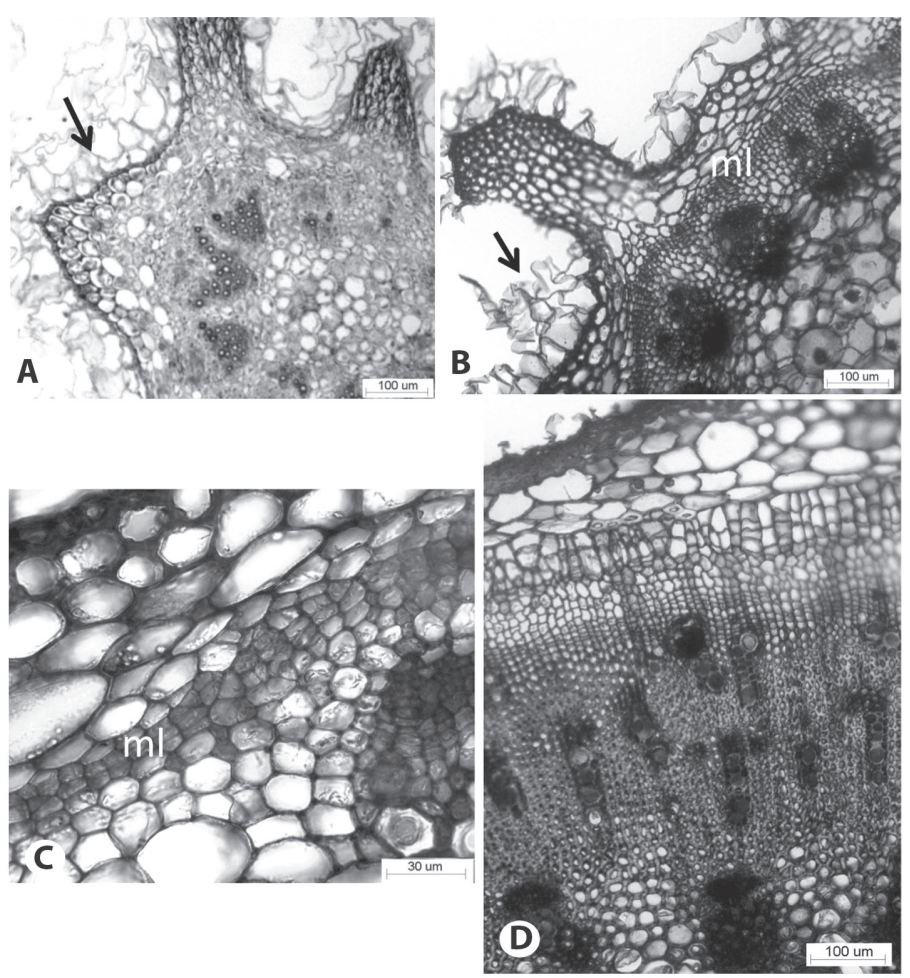

Fig. 2. Secciones transversales a lo largo del eje caulinar en A. oestophora. A. Entrenudo apical; nótese eustela típica, crestas y tricomas (flechas). B. Nótese colénquima en cresta y desarrollo del meristema lateral (ml) por fuera de los haces vasculares. C. detalle de la anterior. D. Producción de tejido vascular y conjuntivo a partir del meristema lateral; nótense haces primarios, en la zona más interna.

Fig. 2. Transversal sections along the stem in A. oestophora. A. Apical internode showing typical eustele, crest and trichomes (arrows). B. Note collenchyma in crest and lateral meristem $(\mathrm{ml})$ development on the outside of the vascular bundles. C. Detail of the previous. D. Vascular and conjunctive tissue produced by lateral meristem; showing primary vascular bundles en the innermost area. 
ubican tres más grandes de manera semejante a lo explicado antes y dos-tres, más pequeños, en posición contraria. En ambas especies, en los laterales de los arcos se ubican dos capas de parénquima clorofiliano, la externa, con células alargadas, dispuestas radialmente y la interna de células redondeadas y contenido denso, pero ambas capas están interrumpidas hacia las caras adaxial y abaxial.

Los tallos jóvenes de ambas especies presentan prominencias o crestas (Fig. 2A, Fig. 2B); están bordeados por epidermis uniestratificada con abundantes tricomas semejantes a los descritos para las hojas. Subepidérmicamente, se localiza parénquima con células redondeadas a alargadas periclinalmente; principalmente en las crestas es evidente colénquima angular (Fig. 2B, Fig, 2C, Fig. 2D). El sistema vascular primario está constituido por haces colaterales organizados en una eustela típica
(Fig. 2A, Fig. 2B), en ocasiones con grupos de fibras perifloemáticas. En la zona central se localiza la médula, constituida por células parenquimáticas (Fig. 2A, Fig. 2B). Tempranamente ocurre la diferenciación de un meristema lateral, a partir de células parenquimáticas de la región interna de la corteza (Fig. 2B, Fig. $2 \mathrm{C})$ y en caso de haber esclerénquima, proviene de aquellas que quedan entre este último tejido y el floema. No se produce crecimiento secundario típico (Fig. 2D, Fig. 3A, Fig. 3B). El crecimiento en grosor ocurre debido a la actividad del meristema lateral, el cual genera inicialmente tejido conjuntivo constituido principalmente por células esclerenquimáticas, y luego xilema hacia adentro y floema hacia afuera a partir de bandas cambiales (Fig. 2D). El meristema lateral se activa repetidas veces produciendo anillos sucesivos, que dejan el floema encerrado entre células parenquimáticas

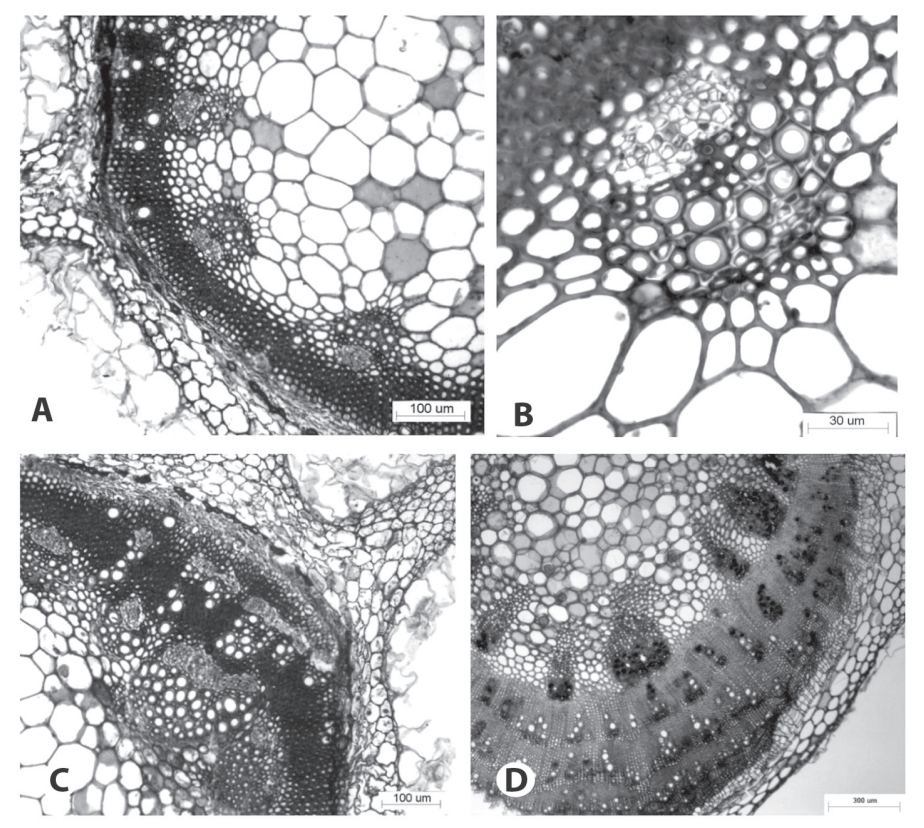

Fig. 3. Secciones transversales a lo largo del eje caulinar en A. cristata y A. oestophora. A-C. A. oestophora, nótese producción de tejido conjuntivo y vascular, a partir del meristema lateral, ausencia de crecimiento secundario típico y tejido conjuntivo, principalmente parenquimático. D. Anillos vasculares con regiones amplias de tejido conjuntivo parenquimático en $A$. cristata.

Fig. 3. Transversal sections along the stem in A. cristata and A. oestophora. A-C. A. oestophora showing vascular and conjunctive tissue produced by lateral meristem, absence of typical secondary growth and conjunctive tissue schlerenchymatous. D. Succesive vascular rings with wider regions of conjunctive tissue parenchymatous in $A$. cristata. 
o esclerenquimáticas y xilema, denominado floema incluso del tipo foraminado concéntrico, ya que las porciones floemáticas se distribuyen en anillo en la sección transversal (Fig. 3C, Fig. 3D).

Las raíces en estructura primaria (Fig. 4A, Fig. 4B) tienen una rizodermis de paredes delgadas sin pelos absorbentes. La corteza es estrecha con dos a tres capas de parénquima y la endodermis uniestratificada. El cilindro vascular está limitado por una capa de periciclo y está constituido por un haz con dos arcas xilemáticas. El desarrollo de estructura secundaria en este órgano ocurre tempranamente (Fig. 4C), inicialmente a partir de cambium vascular diferenciado en la zona del haz y de células del periciclo; no obstante, este crecimiento se detiene y se diferencia un meristema lateral a partir de células del periciclo y del parénquima próximo a éste. Dicho meristema permanece y produce sucesivas capas de tejidos vasculares, separadas e interconectadas por tejido conjuntivo. Destaca la forma de este meristema para producir células en ambas especies, ya que se genera un arreglo histológico diferente en las mismas; en A. cristata son anillos o arcos de xilema secundario y floema secundario delimitados por bandas de tejido conjuntivo principalmente parenquimático (Fig. 4D), mientras que en $A$. oestophora el arreglo semeja haces

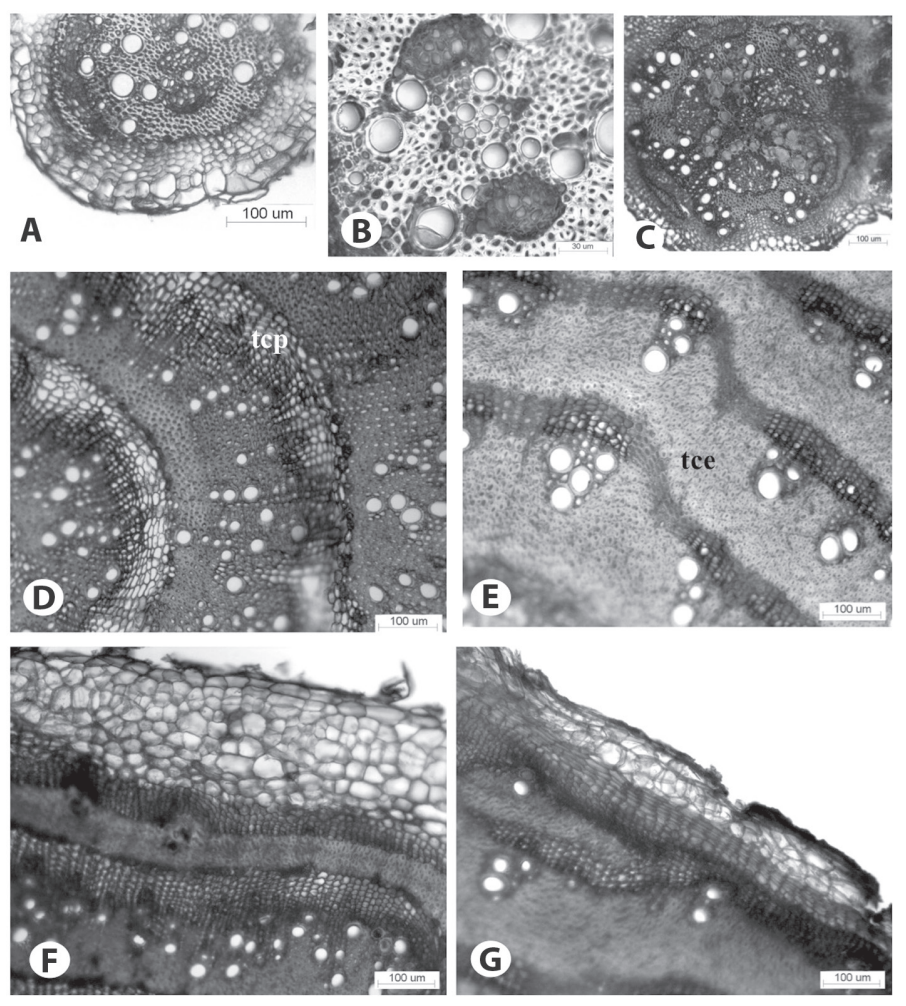

Fig. 4. Secciones transversales de raíces de A. cristata y A. oestophora. A. Estructura primaria en A. cristata. B. Detalle de la anterior; nótese haz radial con dos arcas xilemáticas. C. Estructura secundaria en A. cristata. D-E. Anillos vasculares en $A$. cristata y $A$. oestophora; nótese el arreglo de los tejidos vasculares y el tipo de tejido conjuntivo predominante. F-G. Región externa en crecimiento secundario; nótese la organización de la peridermis. tce: tejido conjuntivo esclerenquimático, tcp: tejido conjuntivo parenquimático.

Fig. 4. Transversals sections of roots of A. cristata and A. oestophora. A. Primary structure in A. cristata. B. Detail of the previous. C. Secondary structure in A. cristata. D-E. Vascular rings in A. cristata and A. oestophora, note the arrangement of vascular tissues and the type of conjunctive tissue predominant. F-G. External region in secondary growth; note the organization of the periderm. tce: conjunctive tissue sclerenchyma, tcp: conjunctive tissue parenchyma. 
vasculares (no equivalentes a éstos) en una matriz de tejido conjuntivo, mayormente esclerenquimática (Fig. 4E, Fig. 5E). El desarrollo de peridermis no fue observado; dicho tejido se localiza en las capas más externas de la corteza, de forma discontinua, y constituida por algunas capas de súber hacia el exterior y de felodermis hacia el interior; el súber está formado por células relativamente grandes y de paredes delgadas (Fig. 4F, Fig. 4G).
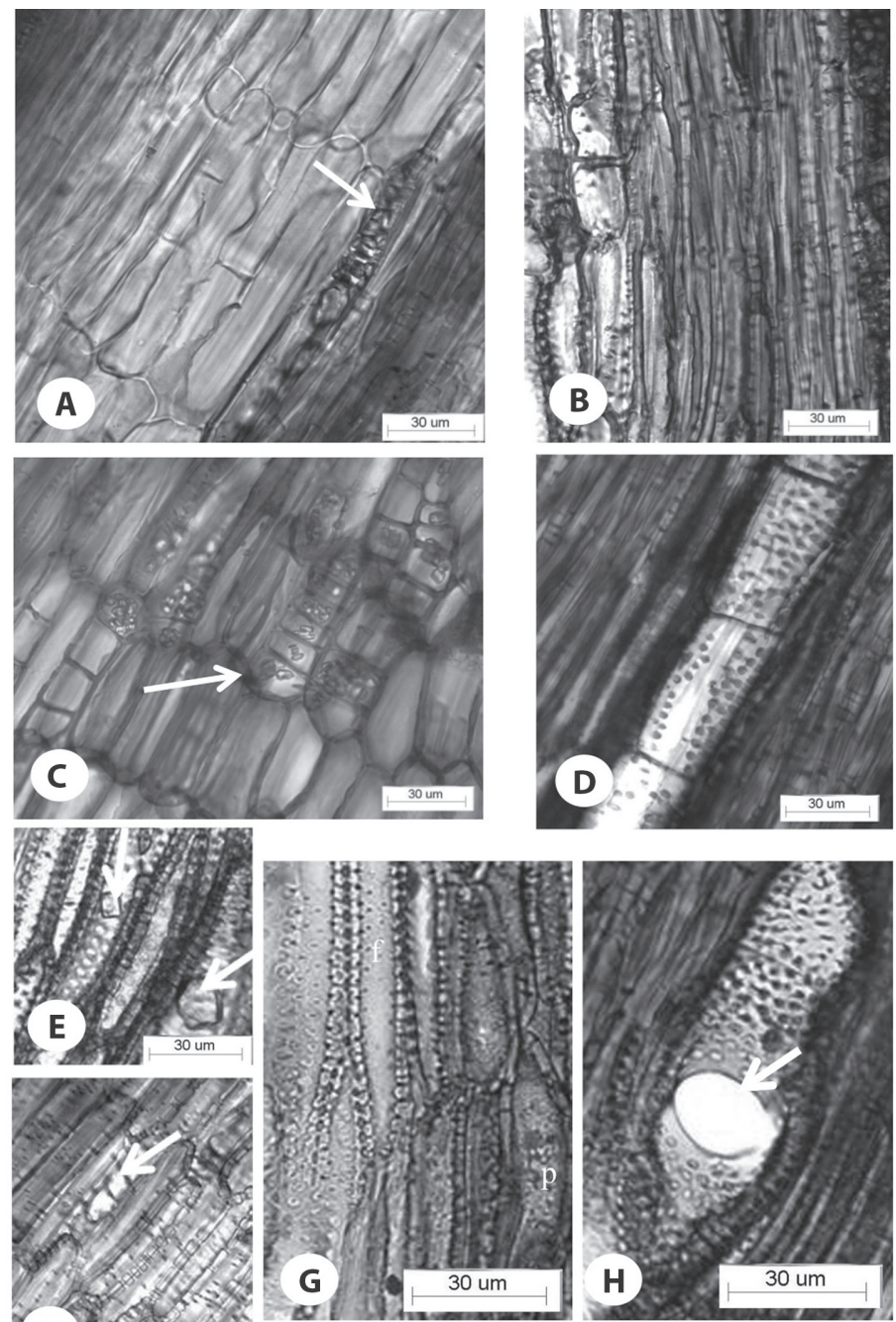

$\mathbf{F}$

Fig. 5. Secciones longitudinales de raíces de dos especies de Atriplex. A-D. A. cristata. A. Tejido conjuntivo parenquimático; nótense cristales en capa límite con anillo vascular (flecha). B. Parénquima axial y fibras cortas. C. Tejido conjuntivo constituido por parénquima fusiforme estratificado; nótense células con cristales en una serie. D. Elementos de vaso cortos con placa de perforación simple. E-I. A. oestophora. E-F. Cristales (flechas) en células conductoras y en parénquima respectivamente. G. Tejido conjuntivo esclerenquimático: fibras (f) y parénquima esclerosado (p). H. Elemento de vaso corto con placa de perforación simple (flecha).

Fig. 5. Longitudinal sections of roots of two species of Atriplex. A-D. A. cristata. A. Conjunctive tissue parenchyma: note crystals in boundary layer with a vascular ring (arrow). B. Axial parenchyma and short fibers. C. Conjunctive tissue formed for fusiform stratified parenchyma, note crystals cells in serie. D. Shorts vessels elements with simple perforation plate. E-I. A. oestophora. E-F. Crystals (arrows) in the conductor and parenchyma cells, respectively. G. Conjunctive tissue schlerenchymatic: fibers (f) and parenchyma (p). H. Short vessel element with simple perforation plate (arrow). 
El índice de vulnerabilidad calculado en las raíces resultó de 0.12 para $A$. cristata y 0.14 para $A$. oestophora. El xilema en estas dos especies carece de radios y está constituido por fibras cortas (Fig. 5B), traqueidas y elementos de vasos cortos (Fig. 5D, Fig. 5E, Fig. 5F, Fig. $5 \mathrm{G})$ y estrechos con placas de perforación simple (Fig. 5D, Fig. 5E, Fig. 5F, Fig. 5G, Fig. 5H), y parénquima axial conjuntivo fusiforme estratificado, con células de paredes delgadas en $A$. cristata (Fig. 5C) y mayormente gruesas en $A$. oestophora, en este caso asociado a gran cantidad de fibras cortas (Fig. 5G). Ambas especies presentan cristales principalmente prismáticos; en $A$. cristata, ubicados en células parenquimáticas en el límite con el anillo vascular (Fig. 5A) o en células parenquimáticas cortas en una serie de hasta siete células (5C), mientras que en $A$. oestophora se localizan tanto en células parenquimáticas como conductoras (Fig. 5E, Fig. 5F). El floema es incluso del tipo foraminado concéntrico en $A$. oestophora (Fig. 4E), rasgo no observado en $A$. cristata (Fig. 4D).

\section{DISCUSIÓN}

Los rasgos epidérmicos foliares son relativamente semejantes en las dos especies; no obstante, las células típicas en $A$. cristata aparentemente tienen mayor volumen que las de $A$. oestophora, lo cual puede asociarse con capacidad para almacenar agua. En cuanto a los estomas, presentan el mismo tipo. Ambas especies tienen tricomas vesiculares tanto en sus hojas como en las porciones jóvenes de sus tallos. Tricomas semejantes fueron caracterizados en A. halimus (Mozafar \& Goodin, 1970), indicando su importancia en la remoción de sales de la hoja y en prevenir la acumulación de sales tóxicas en parénquima y tejidos vasculares. Smaoui, Barhoumi, Rabhi, y Abdelly (2011) estudiaron bajo microscopía óptica y electrónica los tricomas presentes en esa especie, así como las vías de movilización de las sales. Tricomas con esa misma morfología, fueron reportados por Trougthon y Card (1974) en $A$. buchananii. En los tallos más jóvenes y hojas de A. lampa (Frayssinet et al., 2007) se cita la presencia de estructuras semejantes a las aquí descritas, denominándolas glándulas de sal; asimismo, en A. sagittifolia (D'Ambrogio, Fernández, González, Furlan, \& Frayssinet, 2000) citan su ocurrencia. Wahid (2003) destaca la importancia de estas estructuras en especies de Atriplex, caracterizando las vías y secreción de iones. Sayed-Hussin (2007) caracterizó estos tricomas en A. nummularia Lindl. y A. leucoclada Boiss. y confirmó, mediante un análisis de espectroscopía de energía dispersiva de rayos $\mathrm{X}$, que las concentraciones de $\mathrm{Na}^{+} \mathrm{y}$ Cl- son más altas en estos tricomas que en el resto de células que conforman la hoja, lo cual reafirma la función asignada a los mismos. En A. tatarica L. también se han observado estos tricomas, indicándose además que la presencia de glándulas secretoras de sal es considerada actualmente la segunda gran estrategia de las halófitas, y que generalmente ocurren en aquellas especies que no cuentan con mecanismos de regulación interna (Grigore \& Toma, 2007). Sin embargo, en este caso se presentan ambas estrategias, ya que las especies bajo estudio tienen ese tipo de tricomas pero, además parecen tener mecanismos de regulación como lo son la presencia de células altamente vacuoladas, en $A$. cristata a nivel de epidermis y en $A$. oestophora en lo que posiblemente sea una hipodermis; dichas células les permiten almacenar considerables cantidades de agua, que pueden ser movilizadas para mantener los procesos vitales; este rasgo es referido como adaptación a ambientes áridos (Fahn \& Cutler, 1992). Asimismo, se ha indicado que la suculencia facilita la dilución de los iones y por tanto evita el efecto tóxico de los mismos (Sayed-Hussin, 2007).

En $A$. oestophora existe probablemente una hipodermis en posición subepidérmica; este tejido también fue observado en $A$. lampa (Frayssinet et al., 2007); en ambas especies se caracteriza por ser uniestratificada y constituida por células incoloras. Se ha señalado que este tejido tiene por función economizar agua y actuar en la protección del clorénquima de la excesiva radiación solar (Roth, 1992); asimismo, se puede considerar una adaptación para superar la condición salina, ya que permite la 
presencia de iones tóxicos dentro de compartimentos celulares (vacuolas) donde se mantienen diluidos (Wahid, 2003; Sayed-Hussin, 2007). Su presencia en una sola de las especies constituye un carácter de valor diagnóstico para delimitarlas taxonómicamente.

Las hojas de las especies estudiadas muestran anatomía Kranz, pudiendo catalogarse como subtipo atriplicoide, de acuerdo con la propuesta de Carolin, Jacobs, y Vesk (1975) y tal como ha sido observado en $A$. lampa (Freyssinet et al., 2007) y en $A$. tatarica (Grigore \& Toma, 2007); este subtipo se caracteriza por tener los haces vasculares rodeados por una vaina parenquimática y un arreglo radial de las células del mesofilo. Las células de la vaina tienen paredes más gruesas y mayor contenido amiláceo que las del mesofilo. Carolin et al. (1975) indicaron que los cloroplastos en las células de la vaina tienen grana bien formadas y un mayor número de mitocondrios, que aquellas del mesofilo; sin embargo, estos rasgos no pudieron ser constatados en este estudio. Se ha señalado que el subtipo atriplicoide es el más común y que desde el punto de vista bioquímico puede tener las vías NADP-ME o NAD-ME (Muhaidat, Sage, \& Dengler, 2007), que corresponden a subtipos dentro de la vía fotosintética $\mathrm{C}_{4}$. No obstante, es necesario realizar pruebas bioquímicas para definir el metabolismo fotosintético de los taxa en estudio. Las plantas con mecanismo fotosintético $\mathrm{C}_{4}$ generalmente están asociadas con hábitats en los que las condiciones de vida son severas, mostrando alta tolerancia a sequía, altas temperaturas, alta irradiación y salinidad (Grigore \& Toma, 2007).

La alta deposición de cristales en las hojas y tallos de las dos especies puede considerarse un mecanismo de osmo-regulación, al controlar la concentración interna de sales que pueden producir toxicidad, tal como se ha referido para especies de plantas que crecen en el desierto de Atacama en Chile (Poblete, Campos, González, \& Montenegro, 1991). Sin embargo, llama la atención que en $A$. cristata la deposición parece ser mayor en tallos y raíces, mientras que en $A$. oestophora esto ocurre a nivel de hojas; este aspecto requiere ulteriores investigaciones.
Heklau, Gasson, Schweingruber, y Baas (2012) señalaron que los cristales de oxalato de calcio son prominentes en las Chenopodiaceae, siendo el tipo drusa, el cristal más frecuente. No obstante, en las especies estudiadas predominan drusas en hojas y prismas en tallos.

El número de haces vasculares y su organización a nivel de la región basal y media del nervio central son características importantes de considerar en la delimitación de las especies. No hay referencias sobre este aspecto para el género Atriplex, por lo cual es necesario revisar este rasgo en otras especies a fin de verificar su valor diagnóstico.

Los tallos jóvenes tienen características propias de una dicotiledónea y en particular de otras Chenopodiaceae descritas (Wang et al., 1997; D'Ambrogio et al., 2000; Frayssinet et al., 2007).

Las raíces diarcas pudiesen ser propias de este género, ya que han sido descritas para A. sagittifolia (D'Ambrogio et al., 2000) y $A$. lampa (Frayssinet et al., 2007); se debe destacar la presencia de una corteza de pocas capas de células, lo cual puede constituir una estrategia para acortar la distancia de recorrido del agua hasta la estela, tal como ha sido señalado por Wahid (2003) para plantas de zonas salinasdesérticas. El arreglo estructural de este órgano en estructura primaria se asemeja bastante al descrito para la Chenopodiaceae Salsola kali subsp. ruthenica (Bercu \& Bavaru, 2004).

Las dos especies presentan variantes en la actividad del cambium vascular en sus tallos y raíces. En el caso de los tallos, contrario a lo citado en la literatura para otras especies de Chenopodiaceae (Grigore \& Toma, 2007), no se produce crecimiento en grosor por la actividad del cambium típico, ni siquiera en forma incipiente; sin embargo, concuerda con lo descrito para A. lampa al producirse el crecimiento secundario de sus tallos (Frayssinet et al., 2007). En tallos y raíces de las especies estudiadas, se forma un meristema lateral que es capaz de producir varios anillos de tejido vascular y conectivo; no obstante el patrón de organización de los mismos, tal como se explicó, es diferente en las dos especies estudiadas, 
por lo que puede constituir un carácter de importancia taxonómica. Metcalfe \& Chalk (1950) señalaron que el carácter anatómico común más importante entre las Chenopodiaceae y Amaranthaceae es el desarrollo de crecimiento secundario anómalo; denominado actualmente crecimiento secundario con variantes cambiales. Heklau et al., (2012) señalaron que los cambium sucesivos y el floema incluso son rasgos típicos en Chenopodiaceae.

La formación de anillos vasculares se ha referido como una ventaja adaptativa bajo condiciones de estrés hídrico y en particular bajo condiciones salinas (Robert et al., 2011). La alternancia de parénquima con tejido vascular ofrece una alternativa para el almacenamiento de agua, mientras que el tejido fibroso promueve la fuerza mecánica para prolongar la capacidad de conducción (Carlquist, 2007). Por otra parte, los índices de vulnerabilidad calculados indican que ambas especies tienden a asegurar la conducción y no la eficiencia de la misma, ya que poseen vasos estrechos, e inclusive cortos, tal como se deduce de las observaciones. El xilema muestra en sus células rasgos citados en la literatura para Chenopodiaceae (Heklau et al., 2012).

Los resultados revelan rasgos estructurales en los diferentes órganos estudiados que revisten valor taxonómico, ya que permiten distinguir las especies, pudiendo destacar a nivel de hoja la posible presencia de hipodermis, el número de haces vasculares y su organización a nivel del nervio medio, así como la diferenciación de colénquima en esta parte de la hoja. En el caso de las raíces, destacan el arreglo del xilema y floema en los anillos de crecimiento, la naturaleza del tejido conjuntivo, así como la presencia de floema incluso en una de las especies.

Por otra parte, las especies bajo estudio muestran varios caracteres anatómicos típicos de plantas halófilas y xerófilas, como son: alta densidad de tricomas, que a su vez actúan como glándulas secretoras de sal, abundancia de esclerénquima en tallos y raíces, tejidos reservantes de agua, anatomía Kranz en hojas, región cortical estrecha en raíces jóvenes, presencia de variantes cambiales en tallos y raíces, vasos cortos y estrechos.

\section{RESUMEN}

En Venezuela, Atriplex está representado por $A$. cristata y $A$. oestophora, siendo esta última endémica, las mismas habitan zonas costeras con altas temperaturas, alta radiación solar y suelos arenosos con alto contenido de sales. Se caracterizaron anatómicamente sus órganos vegetativos con el fin de aportar rasgos para delimitarlas taxonómicamente y precisar caracteres que contribuyan a su adaptabilidad a las condiciones edafoclimáticas imperantes en su hábitat. El material vegetal fue recolectado en tres individuos de cada especie en Punta Taima Taima y Capatárida (Falcón). Se recolectaron segmentos de raíces próximos al cuello y al ápice; entrenudos basales, medios y apicales, y hojas ubicadas en la porción media de las plantas. Este material fue fijado en FAA (formaldehido, ácido acético y etanol $70 \%$ ) hasta su procesamiento. Se prepararon láminas semipermanentes y permanentes con secciones transversales y longitudinales hechas a mano alzada o con micrótomo, en este último caso posterior a la inclusión en parafina. Adicionalmente, se realizaron macerados con el fin de obtener las epidermis foliares. Las secciones fueron teñidas con azul de toluidina acuosa ( $1 \%$ ) o con safraninafastgreen, montándolas en agua/glicerina o en bálsamo de Canadá. Se cuantificó el número de vasos y su densidad en los anillos vasculares de las raíces, para calcular el índice de vulnerabilidad. Se encontraron rasgos estructurales de valor taxonómico: la presencia de tejido acuífero en la lámina foliar, el número de haces vasculares y su organización en el nervio medio, así como la diferenciación de colénquima en el mismo; además, el arreglo del xilema/ floema en los anillos de crecimiento, la naturaleza del tejido conjuntivo, así como la presencia de floema incluso, en las raíces. Se detectaron caracteres anatómicos típicos de halófitas y xerófitas, como son: alta densidad de tricomas en hojas y tallos jóvenes, que actúan como glándulas secretoras de sal, abundancia de esclerénquima en tallos y raíces, tejidos reservantes de agua y anatomía Kranz en hojas, región cortical estrecha en raíces jóvenes, presencia de variantes cambiales en tallos y raíces, así como vasos cortos y estrechos en el xilema. El índice de vulnerabilidad indica que ambas especies tienden a asegurar la conducción, pero no la eficiencia del sistema. Las especies de Atriplex que crecen en Venezuela tienen caracteres que permiten su delimitación taxonómica y que facilitan su adaptación a las condiciones particulares de su hábitat.

Palabras clave: anatomía, Atriplex, especies halófitas, hoja, tallo, raíz. 


\section{REFERENCIAS}

Bercu, R. \& Bavaru, E. (2004). Anatomical aspects of Salsola kali subsp. ruthenica (Chenopodiaceae). Phytologia Balcanica, 10(2-3), 227-232.

Carlquist, S. (1977). Ecological factors in wood evolution, a floristic approach. American Journal of Botany, 64(7), 887-896.

Carlquist, S. (2007). Successive cambia revisited: ontogeny, histology, diversity, and functional significance. Journal of the Torrey Botanical Society, 134(2), 301-332.

Carolin, R., Jacobs, S., \& Vesk, M. (1975). Leaf structure in Chenopodiaceae. Botanische Jahrbücher für Systematik, 95(2), 226-255.

Cuénoud, P., Savolainen, V., Chatrou, L. W., Powell, M. Grayer, R. J., \& Chase M. W. (2002). Molecular phylogenetics of Caryophyllales based on nuclear 18S rDNA and plastid rbcL, atpB, and matK DNA sequences. American Journal of Botany, 89(1), 132-144.

D’Ambrogio, A., Fernández, S., González, E., Furlan, I., \& Frayssinet, N. (2000). Estudios morfoanatómicos y citológicos en Atriplex sagittifolia (Chenopodiaceae). Boletin Sociedad Argentina de Botánica, 35(3-4), 215-226.

Enríquez, E., Parra, M. A., \& Ramírez, F. (2011). Producción y valor nutritivo de forraje de Atriplex en un suelo salino. Revista Biotecnia, 13(2), 29-34.

Fahn, A. \& Cutler, D. (1992). Xerophytes. Encyclopedia of plant anatomy. Berlin, Alemania: Gebruder, Borntraeger.

Flores, H. (1992). Taxonomía del grupo Atriplex pentandra (Chenopodiaceae). Anales del Instituto de Biología de la Universidad Autónoma de Mexico, Serie Botánica, 63(2), 155-194.

Frayssinet, N., González, E., D’Ambrogio, A., Fernández, S., \& Furlan, I. (2007). Estudio citológico, exo y endomorfológico en Atriplex lampa (Moq.) D. Dietr. (Chenopodiaceae). Polibotanica, 24, 1-23.

Grigore, M. N. \& Toma, C. (2007). Histo-anatomical strategies of Chenopodiaceae halophytes: adaptive, ecological and evolutionary implications. Wseas Transactions on Biology and Biomedicine, 4(12), 207-218.

Heklau, H., Gasson, P., Schweingruber, F., \& Baas, P. (2012). Wood anatomy of Chenopodiaceae (Amaranthaceae s.1.). International Association of Wood Anatomists Journal, 33(2), 205-232.

Hokche, O., Berry, P., \& Huber, O. (2008). Nuevo catálogo de la flora vascular de Venezuela. Venezuela: Fundación Instituto Botánico de Venezuela.

Howard, R. (1973). The enumeratio and selectarum of Nicolaus von Jacquin. Journal Arnold Arboretum, 54(4), 435-470.
Johansen, D. A. (1940). Plant microtechnique. New York, USA: McGraw Hill.

Kadereit, G., Borsch, T., Weising K., \& Freitag, H. (2003). Phylogeny of Amaranthaceae and Chenopodiaceae and the evolution of $\mathrm{C}_{4}$ photosynthesis. International Journal of Plant Science, 164, 959-986.

Kadereit, G., Mavrodiev, E. V., Zacharias, E. H., \& Sukhorukov, A. P. (2010). Molecular phylogeny of atripliceae (Chenopodioideae, Chenopodiaceae): implications for systematics, biogeography, flower and fruit evolution, and the origin of $\mathrm{C}_{4}$ photosynthesis. American Journal of Botany, 97(10), 1664-1687.

Krauss, E. \& Arduin, M. (1997). Manual básico de métodos en morfología vegetal. Argentina: EDUR, Seropédica.

McArthur, E. D. \& Sanderson, S. C. (1983). Distribution, systematics, and evolution of Chenopodiaceae an overview. In A. R. Tiedemann, E. D. Arthur, H. C. Stutz, R. Stevens, \& K. L. Johnson (Eds.), Proceedings Symposium on the Biology of Atriplex and related Chenopods (pp. 14-24). Provo, Utah, Estados Unidos.

Medina, E., Francisco, A., Wingfield, R., \& Casañas, O. (2008). Halofitismo en plantas de la costa Caribe de Venezuela. Acta Botánica Venezuelica, 31(1), 49-80.

Metcalfe, C. R. \& Chalk, L. (1950). Anatomy of Dicotyledons. Oxford, Reino Unido: Clarendon Press.

Mozafar, A. \& Goodin, J. R. (1970). Vesiculated hairs: A mechanism for salt tolerance in Atriplex halimus L. Plant Physiology, 45, 62-65.

Muhaidat, R., Sage, R., \& Dengler, N. (2007). Diversity of kranz anatomy and biochemistry Int. J. Agri. Biol. in $\mathrm{C}_{4}$ eudicots. American Journal of Botany, 94(3), 362-381.

Mulas, M. \& Mulas, G. (2004). The strategic use of Atriplex and Opuntia to combat desertification. Sassari, Italia: Desertification Research Group, University of Sassari.

Müller, K. \& Borsch, T. (2005). Phylogenetics of Amaranthaceae based on matK/trnK sequence data Evidence from parsimony, likelihood, and Bayesian analyses. Annals of Missouri Botanical Garden, 92(1), 66-102.

Pérez, V. \& Hermann, P. (2009). Comparación anatómica de Nitrophila australis var. australis y Nitrophila occidentalis (Chenopodiaceae). Su importancia taxonómica. Boletín Sociedad Argentina de Botánica, 44(3-4), 329-342.

Poblete, V., Campos, V., González, L., \& Montenegro, G. (1991). Anatomical leaf adaptations in vascular plants of a salt marsh in the Atacama Desert (Chile). Revista Chilena de Historia Natural, 64, 65-75. 
Robert, E., Schmitz, N., Boren, I., Driessens, T., Herremans, K., Mey, J. de, Casteele, E. van de, Beckman, H., \& Koedam, N. (2011). Succesive cambia: a developmental oddity or an adaptative structure? PLoS one, 6(1) e16558.

Roth, I. (1992). Leaf structure: coastal vegetation and mangroves of Venezuela. Berlín, Alemania: Gebr. Borntraeger.

Ruiz-Zapata, T., Castro, M., \& Wingfield, R. (2013, junio). El género Atriplex L. (Amaranthaceae) en Venezuela. Póster presentado al IV Congreso Venezolano de Diversidad Biológica, Falcón, Venezuela.

Smaoui, A., Barhoumi, Z., Rabhi, M., \& Abdelly, C. (2011). Localization of potential ion transport pathways in vesicular trichome cells of Atriplex halimus L. Protoplasma, 248, 363-372.
Sayed-Hussin, S. A. E. (2007). Mechanisms of salt tolerance in the halophytes Atriplex nummularia Lindl. and Atriplex leucoclada Boiss. (Doctoral thesis). Gottfried Wilhelm Leibniz Universität Hannover, Niedersachsen, Germany.

Troughton, J. \& Card, K. A. (1974). Leaf anatomy of Atriplex buchananii. New Zealand Journal of Botany, 12(2), 167-177.

Wahid, A. (2003). Physiological significance of morphoanatomical features of halophytes with particular reference to Cholistan Flora. International Journal of Agriculture and Biology, 5(2), 207-212.

Wang, L., Showalter, A., \& Ungar, I. (1997). Effect of salinity on growth, ion content, and cell wall chemistry in Atriplex prostrata (Chenopodiaceae). American Journal of Botany, 84(9), 1247-1255. 